\title{
PEMILIHAN MEREK BERAS YANG DIMINATI KONSUMEN STUDI KASUS CV BERAS ALAMI MENGGUNAKAN AHP
}

\author{
Agus Salim ${ }^{1}$, Baginda Oloan Lubis ${ }^{2}$ \\ 1,2Universitas Bina Sarana Informatika \\ Email : ${ }^{1}$ agus.salim@bsi.ac.id, ${ }^{2}$ baginda.bio@bsi.ac.id
}

\begin{abstract}
ABSTRAK
Beras merupakan salah satu makan pokok masyarakat pada umumnya, kebutuhan akan pasokan beras semakin meningkat tiap tahunnya. Meningkatnya jumlah penduduk yang terjadi pada wilayah jababeka menjadi ancaman terhadap persediaan pangan pokok. Untuk menentukan Pemilihan Merek Beras dibutuhkan kriteria beras agar dapat menentukan kualitas beras yang terbaik, serta meningkatkan penjualan. Sehingga dapat memenuhi kebutuhan konsumen terhadap beras. Dalam pemilihan merek beras di CV Beras Alami menggunakan sistem voting, ini jelas kurang valid dalam pemilihannya karena bersifat subjektif. Metode Analytical Hierarchy Process (AHP) digunakan sebagai metode untuk pengambilan keputusan, sebagai solusi dalam pemilihan merek beras di CV Beras Alami. Aplikasi Expert Choice, digunakan sebagai penunjang sistem dalam memudahkan penentuan pemilihan merek beras yang diminati oleh konsumen. Hasilnya dapat diketahui selama periode tahun 2018 beras yang banyak di konsumsi adalah Garuda Utama.
\end{abstract}

Kata Kunci: seleksi, , merek, beras, $A H P$

\section{ABSTRACT}

Rice is one of the staple foods of society in general, the need for rice supply is increasing every year. The increasing population in the Jababeka area is a threat to staple food supplies. To determine the selection of Rice Brands, it takes rice criteria in order to determine the best quality of rice, and increase sales. So that it can meet consumer needs for rice. In the selection of rice brands at CV Beras Alami uses a voting system, this is clearly less valid in its election because it is subjective. Analytical Hierarchy Process (AHP) method is used as a method for decision making, as a solution in selecting rice brands in CV Beras Alami. The Expert Choice application is used as a support system to facilitate the selection of rice brands that are in demand by consumers. The results can be known during the 2018 period that rice is widely consumed is Garuda Utama.

Keyword : selection, brand, rice, AHP

Author Korespondensi (Agus Salim)

Email : $\underline{\text { agus.salim@bsi.ac.id }}$

\section{PENDAHULUAN}

Masyarakat pada umumnya mengkonsumsi beras, karena merupakan salah satu makanan pokok penduduk Negara Indonesia, kebutuhan akan pasokan beras tiap tahunnya selalu meningkat. Meningkatnya jumlah penduduk yang terjadi pada wilayah jababeka inilah menjadi alasannya. Ini merupakan ancaman terhadap persediaan pangan pokok. Untuk memenuhi persediaan pangan beras dan juga kesetabilan harga beras maka CV Beras Alami ikut berperan dalam distribusi pasokan beras, persediaan maksimum minimum, harga beras, dan lain-lain. CV Beras Alami mendistribusikan beras yang bermerek "GARUDA" yang tediri dari beberapa macam tipe beras yaitu GARUDA Utama, GARUDA Platinum, GARUDA Super dan GARUDA Pera. Kualitas beras yang dimiliki oleh CV ini, lebih bagus dari pesaing lainnya. Karena itu, kami ingin mengetahui lebih jauh akan minat dan kualitas yang di inginkan oleh konsumen, dan untuk memberikan masukan kepada perusahaan mana yang harus diproduksi lebih banyak untuk meminimalisir kerugian.

Ditilik dari permasalahan diatas, penulis menyarankan penggunaan metode Analytical Hierarchy Process (AHP), untuk pemilihan beras yang diminati konsumen, selanjutnya, dimana proses awal penulis akan membuat 
hirarki terlebih dahulu kemudian melakukan penyebaran kuisioner yang akan diisi oleh konsumen, kemudian metode Analytical Hierarchy Process (AHP) digunakan pada perhitungan untuk mendukung sistem pendukung keputusan (SPK). Sistem pendukung keputusan memberi kebutuhan informasi, bentuk model, dan proses manipulasi data dalam proses pengambilan keputusan baik pada situasi yang tidak terstruktur ataupun situasi yang semi terstruktur, dimana kondisinya tidak semua orang tahu secara pasti, bagaimana sebuah keputusan dibuat[1]. Metode Analytical Hierarchy Proses (AHP), sangat tepat digunakan untuk pengambilan keputusan yang didalamnya terdapat multi-kriteria dan alternatif pilihan. Terlebih lagi metode ini mampu menunjukkan perbandingan antar kriteria yang ada[2]. Penelitian sebelumnya menjelaskan bahwa Secara umum SPK dapat diartikan sebagai sistem yang dimaksudkan untuk mendukung para pengambil keputusan manajerial dalam situasi keputusan semi terstruktur. SPK dimaksudkan untuk menjadi alat bantu bagi para pengambil keputusan untuk memperluas kapabilitas mereka, namun tidak untuk menggantikan penilaian mereka[3]. Kemudian penelitian yang dilakukan oleh [4] menjelaskan bahwa Analytical Hierarchy Process (AHP) adalah salah satu metode dalam proses pengambilan keputusan dengan peralatan utamanya adalah sebuah hierarki fungsional dengan input utamanya persepsi manusia. Dengan menggunakan hierarki, suatu masalah yang kompleks dan tidak terstruktur diatur menjadi suatu bentuk hierarki.

\section{METODOLOGI}

Penyelisaian analisis data pada AHP memiliki beberapa tahapan seperti berikut : decompotition, comparative judgment, synthesis of priority, dan logical consistency [5] serta terakhir adalah kesimpulan.

\section{Decompotition}

Berpedoman pada kriteria dan alternatif yang telah diolah maka disusun hirarki agar memudahkan dalam pengolahan data. Penyusunan hirarki menjadi penting karena untuk mencegah terjadinya kesalahan yang akan berakibat pada konsistensi data. Maka dibuatlah struktur hirarki yang mendeskripsikan tujuan dari penelitian ini. Hirarki tersebut dibuat berpedoman pada kriteria, sub kriteria serta alternatif.[2]

Mendefinisikan persoalan, dengan cara memecah persoalan yang utuh menjadi unsurunsurnya dan di gambarkan dalam bentuk hirarki. Terlihat pada Gambar satu.

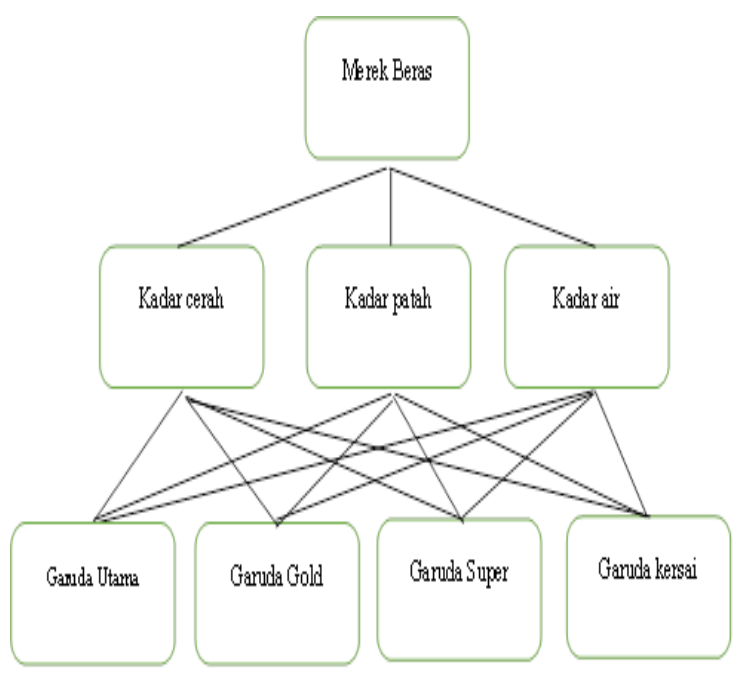

Sumber: Hasil Olahan Data (2018)

Gambar 1. Decompotition

\section{Comparative Judgement}

Kegiatan di tahap ini adalah penentuan prioritas elemen.

Tabel 1. Matriks Perbandingan
Berpasangan[6]
Tujuan $\quad$ kriteria x kriteria y kriteria $\mathrm{z}$

kriteria $\mathrm{x}$

kriteria y

kriteria $\mathrm{z}$

Tabel 2. Skala Kuantitatif Sistem Pendukung Keputusan[2]

Intensitas keterangan

keterangan 


kriteria yang satu sedikit
lebih penting dari pada
kriteria lainnya

$5 \quad$ kriteria yang satu lebih penting dari kriteria lainnya

$7 \begin{aligned} & \text { kriteria yang satu jelas sangat } \\ & \text { penting daripada kriteria } \\ & \text { lainnya }\end{aligned}$

$9 \begin{aligned} & \text { kriteria yang satu mutlak } \\ & \text { sangat penting daripada } \\ & \text { kriteria lainnya }\end{aligned}$

\section{2, 4, 6, 8 Nilai pertimbangan di antara dua nilai yang berdekatan}

\section{kebalikan Jika kegiatan A mendapat satu angka dibandingkan dengan kegiatan $\mathrm{B}$, maka $\mathrm{B}$ memiliki nilai sebaliknya dibanding dengan $\mathrm{A}$.}

\section{Syntesis of Priority}

Keseluruhan prioritas yang ada merupakan perpaduan dari pasangan yang dibandingkan, yang diproses untuk dipertimbangan dengan cara- cara seperti dibawah ini :

a. Jumlahkan matriks, dengan langkah setiap nilai dari setiap kolom dijumlahkan.

b. Normalisasi matriks yang diperoleh merupakan hasil perhitungan dari nilai-nilai pada kolom dibagi dengan total kolom yang terkait.

c. Nilai rata-rata adalah penjumlahan dari setiap matriks kemudian dibagi dengan jumlah kriteria.

\section{Consistency}

Hasil yang valid atau validitas data diperoleh dari pentingnya konsistensi yang didapat dari hasil perhitungan. Pengukuran konsistensi yang akurat pada AHP dapat dilihat dari rasio konsistensi (consistency ratio). Langkah untuk mengukur atau menghitung nilai rasio konsistensi, yaitu :

a. Prioritas relative kriteria pertama dikalikan dengan nilai dari kolom pertama, prioritas relative kriteria kedua dikalikan dengan nilai dari kolom kedua dan seterusnya.

b. Setiap baris yang ada dijumlahkan.

c. Hasil dari penjumlahan point b, dibagi dengan kriteria prioritas relatif yang terkait.

d. Hasil dari point $\mathrm{c}$, dibagi dengan sejumlah kreteria yang ada, inilah yang disebut dengan eigen value ( $\lambda \max )$.

e. Baru bisa dihitung indeks konsistensi-nya (consistency index), menggunakan rumus $:[7]$

$$
\begin{aligned}
& \mathrm{CI}=(\lambda \max -n) /(\mathrm{n}-1) \\
& \mathrm{CR}=\mathrm{CI} / \mathrm{RC}
\end{aligned}
$$

Catatan :

$\mathrm{CR}=$ Consistency Ratio, $\mathrm{CI}=$ Consistency Index, $\mathrm{RC}=$ Random Consistency. Setiap nilai Random Consistency mengacu pada tabel tiga.

Tabel 3. Random Consistency[6]

\begin{tabular}{lllllllllll}
$\mathrm{N}$ & 1 & 2 & 3 & 4 & 5 & 6 & 7 & 8 & 9 & 10 \\
\hline & & & & & & & & & & \\
$\mathrm{R}$ & 0 & 0 & 0,5 & 0,9 & 1,1 & 1,2 & 1,3 & 1,4 & 1,4 & 1,4 \\
$\mathrm{C}$ & & & 8 & 0 & 2 & 4 & 2 & 1 & 5 & 9
\end{tabular}

\section{Kesimpulan}

Membuat kesimpulan didasarkan dari hasil analisa dan proses pengolahan data, kemudian diajukan saran-saran yang bisa dijadikan patokan untuk mengambil keputusan, kepada CV Beras Alami.

\section{HASIL DAN PEMBAHASAN}

\section{Decomposition}

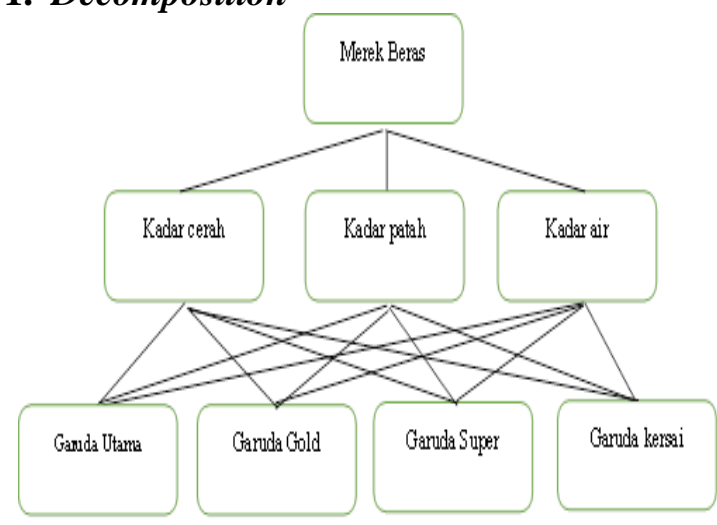

Gambar 2. Hierarki Pemilihan Merek Beras 
Penjelasan Hierarki Pemilihan Merek Beras gambar dua, Tujuan utamanya adalah menentukan merek beras produksi CV Beras Alami, yang diminati oleh konsumen. Kriteria utama terbagi tiga yaitu kadar cerah, kadar patah dan kadar cair. Masing-masing akan ditentukan sub kriteria berdasarkan tingat kadarnya yang terdapat dalam beras Garuda. Kemudian dicari alternatif merek seri beras yang terbaik dengan kualitas terbaik dari masing-masing merek beras yaitu Garuda Utama, Garuda Gold, Garuda Super dan Garuda kersai.

\section{Comparative Judgment}

Melakukan perbandingan dengan kriteria yang telah ditentukan. Berikut adalah hasil dari perbandingan kriteria yang dibahas :

Tabel 4. Perbandingan Matrik Berdasarkan Kriteria Utama

\begin{tabular}{lccc}
\hline Kriteria & Kadar cerah & Kadar patah & Kadar air \\
\hline Kadar cerah & 1,000 & 2,771 & 0,305 \\
\hline Kadar patah & 0,361 & 1,000 & 0,366 \\
\hline Kadar air & 3,277 & 3,031 & 1,000 \\
\hline & & & \\
Total & 4,637 & 6,801 & 1,671 \\
\hline
\end{tabular}

Sumber : Hasil Olahan Data 2018

Tabel 5. Perbandingan Matrik Berdasarkan Kriteria kadar cerah

\begin{tabular}{lcccc}
\hline Alternatif & $\begin{array}{c}\text { Garuda } \\
\text { utama }\end{array}$ & $\begin{array}{c}\text { Garuda } \\
\text { Gold }\end{array}$ & $\begin{array}{c}\text { Garuda } \\
\text { Super }\end{array}$ & $\begin{array}{c}\text { Garuda } \\
\text { Kersai }\end{array}$ \\
\hline $\begin{array}{l}\text { Garuda } \\
\text { Utama }\end{array}$ & 1,000 & 2,150 & 3,929 & 3,459 \\
\hline $\begin{array}{l}\text { Garuda } \\
\text { Gold }\end{array}$ & 0,465 & 1,000 & 4,272 & 3,325 \\
\hline & & & & \\
$\begin{array}{l}\text { Garuda } \\
\text { Super }\end{array}$ & 0,253 & 0,234 & 1,000 & 0,879 \\
\hline
\end{tabular}

\begin{tabular}{lcccc}
\hline $\begin{array}{l}\text { Garuda } \\
\text { Kersai }\end{array}$ & 0,287 & 0,301 & 1,138 & 1,000 \\
\hline Total & 2,006 & 3,685 & 10,339 & 8,663 \\
\hline $\begin{array}{c}\text { Sumber : Hasil Olahan Data 2018 } \\
\text { Tabel 6. Perbandingan Matrik Berdasarkan } \\
\text { Kriteria kadar patah }\end{array}$ & \\
\hline & $\begin{array}{c}\text { Garuda } \\
\text { Alternatif }\end{array}$ & $\begin{array}{c}\text { Garuda } \\
\text { utama }\end{array}$ & $\begin{array}{c}\text { Garuda } \\
\text { Gold }\end{array}$ & $\begin{array}{c}\text { Garuda } \\
\text { Kersai }\end{array}$ \\
\hline $\begin{array}{l}\text { Garuda } \\
\text { Utama }\end{array}$ & 1,000 & 2,858 & 2,505 & 3,558 \\
\hline $\begin{array}{l}\text { Garuda } \\
\text { Gold }\end{array}$ & 0,350 & 1,000 & 3,479 & 2,440 \\
\hline $\begin{array}{l}\text { Garuda } \\
\text { Super }\end{array}$ & 0,399 & 0,287 & 1,000 & 1,846 \\
\hline $\begin{array}{l}\text { Taruda } \\
\text { Kersai }\end{array}$ & 0,333 & 0,410 & 0,542 & 1,000 \\
\hline & 2,082 & 4,555 & 7,526 & 8,844 \\
\hline Tutal & & & & \\
\hline
\end{tabular}

Sumber : Hasil Olahan Data 2018

Tabel 7. Perbandingan Matrik Berdasarkan Kriteria kadar air

\begin{tabular}{ccccc}
\hline Alternatif & $\begin{array}{c}\text { Garuda } \\
\text { utama }\end{array}$ & $\begin{array}{c}\text { Garuda } \\
\text { Gold }\end{array}$ & $\begin{array}{c}\text { Garuda } \\
\text { Super }\end{array}$ & $\begin{array}{c}\text { Garuda } \\
\text { Kersai }\end{array}$ \\
\hline Garuda Utama & 1,000 & 1,407 & 1,136 & 0,912 \\
\hline Garuda Gold & 0,711 & 1,000 & 1,823 & 1,018 \\
\hline Garuda Super & 0,880 & 0,549 & 1,000 & 0,570 \\
\hline Garuda Kersai & 1,097 & 0,983 & 1,755 & 1,000 \\
\hline Total & 3,688 & 3,939 & 5,714 & 3,499
\end{tabular}

Sumber : Hasil Olahan Data 2018 


\section{Syntesis of Priority}

Tabel 8. Normalisasi Matriks dan Eigen Vektor Berdasarkan Kriteria Utama

\begin{tabular}{lcccc}
\hline Kriteria & $\begin{array}{c}\text { Kadar } \\
\text { cerah }\end{array}$ & $\begin{array}{c}\text { Kadar } \\
\text { patah }\end{array}$ & $\begin{array}{c}\text { Kadar } \\
\text { air }\end{array}$ & $\begin{array}{c}\text { Rata- } \\
\text { rata }\end{array}$ \\
\hline $\begin{array}{l}\text { Kadar } \\
\text { cerah }\end{array}$ & 0,216 & 0,407 & 0,182 & 0,269 \\
\hline $\begin{array}{l}\text { Kadar } \\
\text { patah }\end{array}$ & 0,078 & 0,147 & 0,219 & 0,148 \\
\hline Kadar air & 0,707 & 0,446 & 0,599 & 0,584 \\
\hline
\end{tabular}

Eigen Vector

Sumber : Hasil Olahan Data 2018

Dapat disimpulkan dari tabel diatas, urutan kriteria untuk pemilihan merek beras yang diminati oleh konsumen adalah:

1. Kadar Cerah

2. Kadar Air

3. Kadar Patah

Tabel 9. Normalisasi Matriks dan Eigen Vektor Berdasarkan Kriteria kadar Cerah

\begin{tabular}{|c|c|c|c|c|}
\hline 交 & $\begin{array}{c}\text { Gr. } \\
\text { utama }\end{array}$ & $\begin{array}{c}\text { Gr. } \\
\text { Gold }\end{array}$ & $\begin{array}{c}\text { Gr. } \\
\text { Super }\end{array}$ & $\begin{array}{c}\text { Gr. } \\
\text { kersai }\end{array}$ \\
\hline
\end{tabular}

\begin{tabular}{llllll}
\hline & 0,499 & 0,583 & 0,380 & 0,399 & 0,465 \\
$\begin{array}{l}\text { Garuda } \\
\text { Utama }\end{array}$ & & & & & \\
\hline $\begin{array}{l}\text { Garuda } \\
\text { Gold }\end{array}$ & 0,232 & 0,271 & 0,413 & 0,384 & 0,325 \\
\hline $\begin{array}{l}\text { Garuda } \\
\text { Super }\end{array}$ & 0,126 & 0,064 & 0,097 & 0,101 & 0,097 \\
\hline $\begin{array}{l}\text { Garuda } \\
\text { Kersai }\end{array}$ & 0,143 & 0,082 & 0,110 & 0,115 & 0,113 \\
\hline
\end{tabular}

Eigen Vector

Sumber : Hasil Olahan Data 2018

Dari tabel sembilan, Urutan alternatif untuk pemilihan Merek Beras berdasarkan Kriteria Kadar Cerah adalah:

1. Garuda Utama
2. Garuda Gold

3. Garuda Kersai

4. Garuda Super

Tabel 10. Normalisasi Matriks dan Eigen Vektor Berdasarkan Kriteria kadar Air

\begin{tabular}{lccccc} 
& $\begin{array}{c}\text { Gr. } \\
\text { Utama }\end{array}$ & $\begin{array}{c}\text { Gr. } \\
\text { Gold }\end{array}$ & $\begin{array}{c}\text { Gr. } \\
\text { Super }\end{array}$ & $\begin{array}{c}\text { Gr. } \\
\text { Kersai }\end{array}$ & $\begin{array}{c}\text { Rata- } \\
\text { rata }\end{array}$ \\
& & & & & \\
& & & & & \\
\hline $\begin{array}{l}\text { Garuda } \\
\text { Utama }\end{array}$ & 0,271 & 0,357 & 0,199 & 0,261 & 0,272 \\
\hline $\begin{array}{l}\text { Garuda } \\
\text { Gold }\end{array}$ & 0,193 & 0,254 & 0,319 & 0,291 & 0,264 \\
$\begin{array}{l}\text { Garuda } \\
\text { Super }\end{array}$ & 0,239 & 0,139 & 0,175 & 0,163 & 0,179 \\
\hline $\begin{array}{l}\text { Garuda } \\
\text { Kersai }\end{array}$ & 0,297 & 0,250 & 0,307 & 0,286 & 0,285 \\
\hline
\end{tabular}

Eigen Vector

Sumber : Hasil Olahan Data 2018

Dari data tabel 10 Urutan alternatif untuk pemilihan Merek Beras berdasarkan Kriteria Kadar Air adalah:
1. Garuda Kersai
2. Garuda Utama
3. Garuda Gold
4. Garuda Super

Tabel 11. Normalisasi Matriks dan Eigen Vektor Berdasarkan Kriteria kadar Patah

\begin{tabular}{lccccc}
\hline & $\begin{array}{c}\text { Gr. } \\
\text { utama }\end{array}$ & $\begin{array}{c}\text { Gr. } \\
\text { gold }\end{array}$ & $\begin{array}{c}\text { Gr. } \\
\text { super }\end{array}$ & $\begin{array}{c}\text { Gr. } \\
\text { kersai }\end{array}$ & $\begin{array}{c}\text { Rata- } \\
\text { rata }\end{array}$ \\
& & & & & \\
& & & & & \\
Garuda & 0,480 & 0,627 & 0,333 & 0,402 & 0,461 \\
Utama & & & & & \\
\hline $\begin{array}{l}\text { Garuda } \\
\text { Gold }\end{array}$ & 0,168 & 0,220 & 0,220 & 0,276 & \\
\hline & & & & & 0,281 \\
$\begin{array}{l}\text { Garuda } \\
\text { Super }\end{array}$ & 0,192 & 0,063 & 0,063 & 0,209 & 0,149 \\
\hline & & & & & \\
$\begin{array}{l}\text { Garuda } \\
\text { Kersai }\end{array}$ & 0,160 & 0,090 & 0,090 & 0,113 & 0,109 \\
\hline
\end{tabular}


1,000

Eigen Vector

Sumber : Hasil Olahan Data 2018

Urutan alternatif, dari tabel 11 untuk pemilihan merek beras yang diminati oleh konsumen berdasarkan Kriteria Kadar Air adalah:

1. Garuda Gold

2. Garuda Utama

3. Garuda Super

4. Garuda Kersai

\section{Consistency}

\section{Kriteria Utama}

a. normalisasikan dengan eigen vektor

$$
\left(\begin{array}{lll}
1,000 & 2,711 & 0,305 \\
0,361 & 1,000 & 0,366 \\
3,277 & 3,031 & 1,000
\end{array}\right) \times\left(\begin{array}{l}
0,275 \\
0,150 \\
0,575
\end{array}\right)=\left(\begin{array}{l}
0,866 \\
0,460 \\
1,886
\end{array}\right)
$$

b. hasil perhitungan butir a, dibagi dengan eigen vektor

$$
\left(\begin{array}{l}
0,866 \\
0,460 \\
1,886
\end{array}\right):\left(\begin{array}{l}
0,275 \\
0,150 \\
0,575
\end{array}\right)=\left(\begin{array}{l}
3,149 \\
3,067 \\
3,280
\end{array}\right)
$$

c. $\lambda$ maksimum adalah hasil akhir dari operasi perhitungan yaitu hasil penjumlahan matriks dibagi dengan banyak baris atau kolom. $(3,149+3,067+3,280) / 3=3,165$

Langkah selanjutnya, konsistensi hirarki diuji melalui cara berikut:

a. Perhitungan Cosistency $\mathrm{CI}=(\lambda$ maks $-\mathrm{n} /$ (n-1),

$\mathrm{CI}=(3,165-3) /(3-1)=0,08$

b. Menghitung Consistency $\mathrm{CR}=\mathrm{CI} / \mathrm{RC}$

Dimana RC nilainya mengaju pada tabel 3 berpatokan pada RC Index, mengacu pada $\mathrm{n}$ tertentu. Penulis menggunakan tiga kriteria jadi memakai RC 0,58, maka

$\mathrm{CR}=0,08 / 0,58=0,14$

Nilai $\mathrm{CR}=0,14$ masih berada di kisaran 0,1 (10\%) maka artinya eigen vector yang dihasilkan dapat diandalkan karena pasangan matrik berdasarkan kriteria utama telah dibandingkan dan diisi dengan pertimbangan yang konsisten, jadi kesimpulannya dapat diterima.

\section{Kriteria kadar cerah}

a. normalisasikan dengan eigen vektor

$$
\begin{gathered}
\left(\begin{array}{cccc}
1,000 & 2,360 & 4,347 & 4,056 \\
0,424 & 1,000 & 4,748 & 3,667 \\
0,230 & 0,211 & 1,000 & 1,060 \\
0,247 & 0,277 & 0,943 & 1,000
\end{array}\right) \times\left(\begin{array}{l}
0,487 \\
0,322 \\
0,094 \\
0,097
\end{array}\right) \\
=\left(\begin{array}{l}
2,049 \\
1,330 \\
0,377 \\
0,397
\end{array}\right)
\end{gathered}
$$

b. hasil perhitungan butir a, dibagi dengan eigen vektor

$$
\left(\begin{array}{l}
2,049 \\
1,330 \\
0,377 \\
0,397
\end{array}\right):\left(\begin{array}{l}
0,487 \\
0,322 \\
0,094 \\
0,097
\end{array}\right)=\left(\begin{array}{l}
4,027 \\
4,130 \\
4,011 \\
4,093
\end{array}\right)
$$

c. $\lambda$ maksimum adalah hasil akhir dari operasi perhitungan yaitu hasil penjumlahan matriks dibagi dengan banyak baris atau kolom.

$$
(4,027+4,130+4,011+4,093) / 4=4,110
$$

Selanjutnya menguji konsistensi hirarki melalui cara sebagai berikut:

a. Menghitung Cosistency Index,

$$
\mathrm{CI}=(4,110-4) /(4-1)=0,04
$$

b. Menghitung Random Consistency

Kali ini penulis menggunakan empat kriteria, nilai yang digunakan adalah RC 0,90, maka CR $=0.04 / 0.90=0.04$, Karena nilai CR lebih kecil dari $0,1(10 \%)$ maka preferensi responden adalah konsisten.

\section{Kriteria kadar patah}

a. normalisasikan dengan eigen vektor

$$
\begin{gathered}
\left(\begin{array}{cccc}
1,000 & 2,858 & 2,505 & 3,558 \\
0,350 & 1,000 & 3,479 & 2,440 \\
0,339 & 0,287 & 1,000 & 1,846 \\
0,333 & 0,410 & 0,542 & 1,000
\end{array}\right) \times\left(\begin{array}{l}
0,461 \\
0,281 \\
0,149 \\
0,109
\end{array}\right) \\
=\left(\begin{array}{l}
2,025 \\
1,227 \\
0,615 \\
0,458
\end{array}\right)
\end{gathered}
$$

b. hasil perhitungan butir a, dibagi dengan eigen vektor 


$$
\left(\begin{array}{l}
2,025 \\
1,227 \\
0,615 \\
0,458
\end{array}\right):\left(\begin{array}{l}
0,461 \\
0,281 \\
0,149 \\
0,109
\end{array}\right)=\left(\begin{array}{l}
4,393 \\
4,367 \\
4,128 \\
4,202
\end{array}\right)
$$

c. $\lambda$ maksimum adalah hasil akhir dari operasi perhitungan yaitu hasil penjumlahan matriks dibagi dengan banyak baris atau kolom.

$$
(4,393+4,367+4,128+4,202) / 4=4,272
$$

Langkah yang dikerjakan berikutnya, uji konsistensi hirarki dengan cara sebagai berikut:

a. Menghitung Cosistency Index, $\mathrm{CI}=(4,272-4) /(4-1)=0,09$

b. Menghitung Random Consistency

Masih menggunakan empat kriteria ( $\mathrm{RC} 0,90)$ maka $\mathrm{CR}=0.09 / 0.90=0.1$, Karena nilai CR sama dengan $0,1(10 \%)$ maka preferensi responden adalah konsisten.

\section{Kriteria kadar air}

a. normalisasikan dengan eigen vektor

$$
\begin{gathered}
\left(\begin{array}{cccc}
1,000 & 1,407 & 1,136 & 0,912 \\
0,711 & 1,000 & 1,823 & 1,018 \\
0,880 & 0,549 & 1,000 & 0,570 \\
1,097 & 0,983 & 1,755 & 1,000
\end{array}\right) \times\left(\begin{array}{l}
0,272 \\
0,264 \\
0,179 \\
0,285
\end{array}\right) \\
=\left(\begin{array}{l}
1,107 \\
1,074 \\
0,726 \\
1,157
\end{array}\right)
\end{gathered}
$$

b. hasil perhitungan butir a, dibagi dengan eigen vektor

$$
\left(\begin{array}{l}
1,107 \\
1,074 \\
0,726 \\
1,157
\end{array}\right):\left(\begin{array}{l}
0,272 \\
0,264 \\
0,179 \\
0,285
\end{array}\right)=\left(\begin{array}{l}
4,070 \\
4,068 \\
4,056 \\
4,060
\end{array}\right)
$$

c. $\lambda$ maksimum adalah hasil akhir dari operasi perhitungan yaitu hasil penjumlahan matriks dibagi dengan banyak baris atau kolom.

$$
(4,070+4,068+4,056+4,060) / 4=4,063
$$

Berikutnya melakukan, uji konsistensi hirarki dengan cara sebagai berikut:
a. Menghitung Cosistency Index, $\mathrm{CI}=(4,0632-4) /(4-1)=0,02$
b. Menghitung Random Consistency

Masih dengan empat kriteria (RC 0,90) maka $\mathrm{CR}=0.02 / 0.90=0.02$, Karena nilai CR lebih kecil dari 0,1 (10\%) maka preferensi responden adalah konsisten.

Tahapan berikutnya melakukan perhitungan akhir untuk pengambilan keputusan.

$$
\left(\begin{array}{ccc}
0,465 & 0,451 & 0,305 \\
0,325 & 0,286 & 0,264 \\
0,097 & 1,152 & 1,000 \\
0,113 & 0,111 & 0,285
\end{array}\right) \times\left(\begin{array}{l}
0,275 \\
0,150 \\
0,575
\end{array}\right)=\left(\begin{array}{l}
0,352 \\
0,284 \\
0,160 \\
0,212
\end{array}\right)
$$

Berasarkan perhitungan diatas, dapat disimpulkan bahwa dasar eigen vector keputusannya adalah :

1. Garuda Utama memiliki bobot prioritas tertinggi yaitu $0,352=35 \%$

2. Garuda Gold memilki bobot prioritas kedua yaitu $0,284=28 \%$

3. Garuda Super memilki bobot prioritas keempat yaitu $0,160=16 \%$

Garuda Kersai memiliki bobot prioritas ketiga yatu $0,212=21 \%$

Jika digambarkan dalam bentuk grafik akan tampak jumlah prosentasenya seperti gambar tiga. :

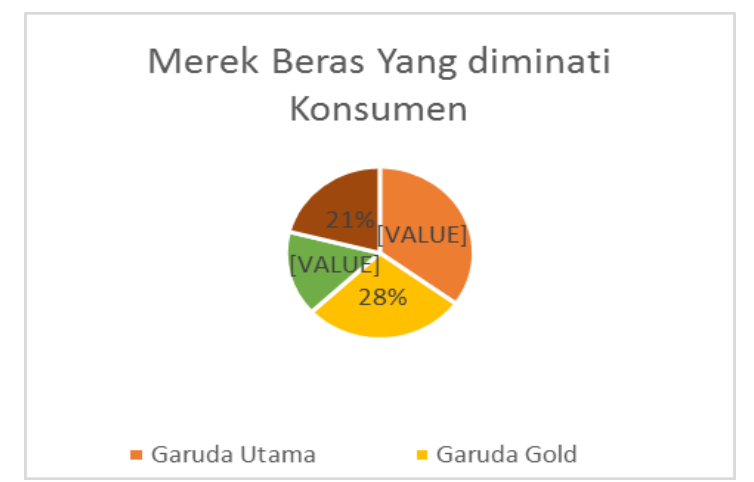

Gambar 3 Grafik Eigen Vector Keputusan (Sumber Data Olahan 2018)

Berdasarkan grafik pada gambar 3, maka pihak CV Beras Alami dapat mengetahui bahwa merek beras yang paling diminati oleh konsumen adalah Garuda Utama. Untuk memastikan hasil yang didapatkan diatas, maka langkah penting berikutnya adalah Rasio Konsistensi Hirarki (CRH) diuji konsistensinya [7]. Untuk melalukan proses pengujian $\mathrm{CRH}$ ini, menggunakan rumus yang ada yaitu: 


$$
\mathrm{CRH}=\mathrm{M} / \overline{\mathrm{M}}
$$

Detil atau rincian perhitungan dapat dilihat pada gambar empat.

$$
\begin{aligned}
& \mathrm{M}=\mathrm{CI} \text { Level } 1+(\text { Eigen Vektor LLevel } 1)(\mathrm{CI} \text { Level } 2) \\
& \mathrm{M}=0.09+(0,269+0,148+0,584) \\
& 0,\left(\begin{array}{l}
0,04 \\
0,09 \\
0,02
\end{array}\right)
\end{aligned}
$$

$\mathrm{M}=0,126$

$\bar{M}=$ RC Level $1+($ Eigen Vektor Level 1) (RC Level 2)

$\mathrm{M}=0,58$

$$
+(0,269+0,148+0,584)\left(\begin{array}{l}
0,90 \\
0,90 \\
0,90
\end{array}\right)
$$

$$
\begin{aligned}
& \overline{\mathrm{M}}=1,481 \\
& \mathrm{CRH}=0,126 / 1,481=0.085
\end{aligned}
$$

Gambar 4. Perhitungan Rasio

Dari perhitungan diatas (gambar empat) diperoleh nilai CRH adalah 0,085. Berarti lebih kecil dari 0.1 maka kesimpulan yang dihasilkan dapat diterima, karena secara keselurhan hirarki bersifat konsisten

\section{SIMPULAN DAN SARAN}

Jika terdapat banyak atau beberapa kriteria dan atau alternatif pilihan dalam Proses pengambilan keputusan maka metode yang tepat adalah AHP. Metode ini secara jelas mampu memperlihatkan perbandingan antar kriteria yang ada. Sehingga pengambilan keputusan pemilihan terhadap suatu produk dapat mudah dilakukan oleh siapapun. Hasil dari penelitian ini adalah Beras Garuda Utama yang paling diminati oleh konsumen. Kiranya dapat dijadikan acuan oleh CV Beras Alami untuk produksi berasnya.

Saran untuk pihak CV Beras Alami, setiap keputusan yang akan dibuat, hendaknnya saling berkoordinasi antar pihak yang terkait dan memikirkannya dengan baik untuk menghindari atau mengurangi resiko kerugian dimasa datang.

\section{UCAPAN TERIMA KASIH}

Kepada seluruh pihak yang memberikan kemudahan dan feedback yang membantu, selama penelitian berlangsung khususnya jajaran pimpinan dan karyawan CV Beras Alami

\section{REFERENSI}

[1] Marimin, Teknik dan Aplikasi Pengambilan Keputusan Kriteria Majemuk. Jakarta: Grasindo, 2018.

[2] A. Salim and B. O. Lubis, "Sistem Pendukung Keputusan Pemilihan Jenis Tablet Gaming dengan Menggunakan Analytical Hierarchy Process," Pros. Semin. Nas. Energi Telekomun. dan Otomasi, no. ISBN: 978-602-74127-4-3, pp. 1-9, 2017.

[3] M. Astradanta, I. M. A. Wirawan, and I. K. R. Arthana, "Pengembangan Sistem Penunjang Keputusan Pemilihan Tempat Kuliner Dengan Menggunakan Metode AHP Dan SAW Studi Kasus : Kecamatan Buleleng," Kumpul. Artik. Mhs. Pendidik. Tek. Inform., vol. 5, no. 2, pp. 1-11, 2016.

[4] M. N. Setiawan, "Sistem Pendukung Keputusan Pemilihan Karyawan Teladan di STMIK Balik Papan Berbasis Website," J. Metik, Vol 1 No 1 201, vol. 11, no. 3, pp. 287-301, 2017.

[5] A. Basuki and A. Dwi Cahyani, Sistem Pendukung Keputusan. Yogyakarta: Deepublish, 2016.

[6] H. Pratiwi, Buku Ajar Sistem Pendukung Keputusan. Yogyakarta: Deepublish, 2016.

[7] M. Brunelli, The Fundamentals of Decision Making and Priority Theory with the Analytic Hierarchy Process. Springer, 2015. 